\title{
Efficiency of the anaerobic digestion of amine wastes
}

\author{
Shuai Wang $\cdot$ Jon Hovland $\cdot$ Rune Bakke
}

Received: 5 May 2013/Accepted: 1 July 2013/Published online: 4 August 2013

(C) The Author(s) 2013. This article is published with open access at Springerlink.com

\begin{abstract}
Laboratory-scale anaerobic degradation of monoethanolamine waste (MEAw) with co-substrate organics was conducted at room temperature and organic loading rates from 0.19 to $5.03 \mathrm{~kg} \mathrm{COD} / \mathrm{m}^{3}$ day for 486 days in a hybrid digester. $90 \%$ feed COD conversion to methane was obtained at the lower loads and only $45 \%$ at the highest MEA waste/COD ratio (MEAwr) of 0.62 due to inhibition of methanogenesis. Inhibition at comparable loads decreased with time, implying that the culture adapted to the challenging feed. Methane yield was negatively correlated to MEAwr applied and inhibition avoided at MEAwr $<0.5$. Acetate accumulation implies inhibition of acetoclastic methanogenesis that can be caused by ammonia, a product of MEAw degradation. Moderate total ammonia nitrogen and free ammonia nitrogen accumulation, maximum $2.2 \mathrm{~g} \mathrm{~N} / 1$ and $90 \mathrm{mg} \mathrm{N} / \mathrm{l}$, respectively suggests, however, that other components of MEAw, and/or degradation products of such, also inhibit methanogenesis, disturbing the digester performance.
\end{abstract}

S. Wang $(\bowtie) \cdot$ R. Bakke

Department of Process, Energy, and Environmental Technology, Telemark University College, Kjølnes Ring 56, Postboks 203, 3910 Porsgrunn, Norway

e-mail: wang.shuai@hit.no

R. Bakke

e-mail: Rune.Bakke@hit.no

J. Hovland

Tel-Tek, Kjølnes Ring 30, 3918 Porsgrunn, Norway

e-mail: Jon.Hovland@tel-tek.no
Keywords Ammonia - Anaerobic digestion · $\mathrm{CO}_{2}$ capture $\cdot$ Ethanolamine $\cdot$

Monoethanolamine $\cdot$ Principle component analysis

\section{Introduction}

There has been increasing focus on $\mathrm{CO}_{2}$ capture (CC) as a measure to mitigate greenhouse gas emissions. In $\mathrm{CC}$, alkaline amine solvents used for absorption of $\mathrm{CO}_{2}$ [e.g. monoethanolamine (MEA)] is considered to be the most mature technology (IEA 2012). MEA and other alkanolamines are also commonly used for the absorption of acidic gases $\left(\mathrm{CO}_{2}, \mathrm{H}_{2} \mathrm{~S}\right.$ etc. $)$ from natural gas and in refineries. The solvents are repeatedly used by regeneration through distillation in the capture process (Barchas and Davis 1992). Over time, the amine solvents degrade due to oxidation, thermal degradation, carbamation and reaction with $\mathrm{SO}_{\mathrm{x}}, \mathrm{NO}_{\mathrm{x}}$ and dust in the flue gas as well as by other means (Goff and Rochelle 2004; Davis and Rochelle 2009). A concentrated solution of reclaimer waste accumulates at the bottom of the reclaimer facility after distillation. This concentrated solution is classified as hazardous waste and must be stored and disposed of accordingly.

Biological MEA waste (MEAw) treatment has been suggested and investigated (Hauser et al. 2013; Botheju et al. 2011; Wang et al. 2013). Anaerobic 
digestion $(\mathrm{AD})$ is a means to both break-down wastes and recover energy from it as methane. $\mathrm{AD}$ is a synergistic biological process that involves various types of organisms. AD of MEAw is challenging due to its relatively high $\mathrm{N}: \mathrm{C}$ ratio and high content of complex chemicals. Inhibition and low chemical oxygen demand (COD) removal efficiency was observed at high loading during co-digestion of MEAw with easily degradable organics (Wang et al. 2013). AD is, though, vulnerable to toxic effects from ammonia and feed organics (Chen et al. 2008). Ammonia is a degradation product of MEA that can be inhibitory to the AD process (Hansen et al. 1998). Additionally, chemicals from MEAw may also stress the organisms.

The aim of this study was to examine the anaerobic degradation of MEAw to determine the limitations of waste loading. The study is a continuation of a previously published experiment (Wang et al. 2013) running the reactor for more than a year to investigate how waste degradation limitations change as the culture adapts to the feed. The AD capacity was tested by measuring the methane yield, COD removal efficiency and ammonia and volatile fatty acid (VFA) accumulations. Principle component analysis (PCA) was applied to investigate the relative significance of possible inhibitory compounds.

\section{Materials and methods}

Feed and nutrient

Reclaimer monoethanolamine MEA waste with combined easily-degradable organics was applied as feed substrate (Table 1). The MEAw investigated was collected from a full-scale MEA-based, $\mathrm{CO}_{2}$ capture facility at a coal-fired power plant. The waste contained complex components that were not well identified. The measured COD of the waste varied between 450 and $900 \mathrm{mg} \mathrm{COD} / \mathrm{g}$ waste, the $\mathrm{N}$ content was $~ 7-14 \%(w / w)$ and the MEA accounted from 18 to $30 \%(\mathrm{w} / \mathrm{w})$. Detailed information about similar wastes can be found in Strazisar et al. (2003) and Thitakamol et al. (2007).

Starch, replaced by glucose after 250 days (due to the detection of starch accumulation on the inner wall of the feeding pipe, to avoid flow disturbances and inconsistent mass balances that it could cause), peptone and yeast extract mixture was applied as the co-substrate feed. The co-substrates were used to provide necessary nutrients, minerals and various easily degradable organics to maintain biomass that can tolerate exposure to toxic and inhibitory chemicals from the MEAw. Preliminary but unpublished tests show that methanogenesis cannot be maintained on MEAw alone as feed substrate. Constant concentrations of first starch, then glucose, peptone and yeast extract were used in the whole test period (Table 1). $\mathrm{KH}_{2} \mathrm{PO}_{4}(0.15 \mathrm{~g} / \mathrm{l})$ and $\mathrm{K}_{2} \mathrm{HPO}_{4}(0.15 \mathrm{~g} / \mathrm{l})$ were also added to the feed as buffers.

Feed solutions were prepared by mixing the MEAw and co-substrate in deionized water and stored at $4{ }^{\circ} \mathrm{C}$. The $\mathrm{pH}$ of the feed mixture was around 10-11 (varying depending on the MEAw content).

$10 \mathrm{ml}$ buffer $\left(102 \mathrm{~g} \mathrm{KH}_{2} \mathrm{PO}_{4} / \mathrm{l} ; 131 \mathrm{~g} \mathrm{~K}_{2} \mathrm{HPO}_{4} / \mathrm{l}\right)$ and mineral solutions (Table 2) were added to the system at the start-up of the digester to stabilize $\mathrm{pH}$ and provide the necessary minerals in the pre-adaptation period. No external buffer and minerals were supplied after the initial addition.

\section{Biomass}

A mixture of inocula from various sources were added in the reactor at the commencement of the test. $200 \mathrm{ml}$ of settled fresh granular sludge, with relatively equal size $(\sim 2 \mathrm{~mm})$ from a pulp and paper industrial wastewater treatment Upflow anaerobic sludge blanket reactor (UASB) in Norway, was applied as the main inoculum. Some polluted river bed sludge (Lilleelva river in Porsgrunn, Norway) and biomass from other laboratory experimental tests (aerobic and anaerobic reactors treating domestic wastewater) were also added in the reactor to give higher biomass diversity. No taxonomical classification was carried out. No extra biomass was added after the experiment startup.

\section{Experimental set-up}

The applied anaerobic reactor set-up is shown in Fig. 1. The reactor was made from a transparent acrylic tube, which was divided into two suspended fluidized bed phases by a fixed biofilm phase, making it a hybrid reactor combining attached and suspended biomass. The total working volume was 1.25 l. Magnetic stirring was employed in the bottom suspended phase 
Table 1 Compositions of the feed substrate added during the experimental period

\begin{tabular}{llll}
\hline Component & $\begin{array}{l}\text { Concentration } \\
(\mathrm{g} / \mathrm{l})\end{array}$ & $\begin{array}{l}\text { COD } \\
(\mathrm{g} \text { COD} / \mathrm{l})\end{array}$ & $\begin{array}{l}\text { Nitrogen } \\
\text { concentration } \\
(\mathrm{g} / \mathrm{l})\end{array}$ \\
\hline Starch (glucose) $^{\mathrm{a}}$ & $1.5(1.7)$ & 1.8 & 0 \\
Yeast extract & 3.6 & 3.3 & $0.4^{\mathrm{b}}$ \\
Peptone & 3 & 4.5 & $0.4^{\mathrm{c}}$ \\
MEA waste & $4-25$ & $1.7-15.6$ & $0.6-3.5^{\mathrm{d}}$ \\
Total & $12.1-33.1$ & $11.3-25.2$ & $1.4-4.3$ \\
\hline
\end{tabular}

a Starch was replaced by glucose at 250th day

b Product reference shows a nitrogen concentration of $10.5 \%$ (w/w) in this yeast extract

c Product reference shows a nitrogen concentration of $12-13 \%(\mathrm{w} / \mathrm{w})$ in this peptone. $12.5 \%(\mathrm{w} / \mathrm{w})$ was used in this calculation

d An approximate $\mathrm{N}$ fraction of $14 \%(\mathrm{w} / \mathrm{w})$ was measured and used here

Table 2 Mineral solution composition used at the startup of the digester

\begin{tabular}{lc}
\hline Chemical & Value $(\mathrm{mg} / \mathrm{l})$ \\
\hline $\mathrm{MnSO}_{4} \cdot \mathrm{H}_{2} \mathrm{O}$ & 40 \\
$\mathrm{FeSO}_{4} \cdot 7 \mathrm{H}_{2} \mathrm{O}$ & 2,800 \\
$\mathrm{CuSO}_{4} \cdot 5 \mathrm{H}_{2} \mathrm{O}$ & 60 \\
$\mathrm{NiCl}_{2} \cdot 6 \mathrm{H}_{2} \mathrm{O}$ & 92 \\
$\mathrm{ZnSO}_{4} \cdot 7 \mathrm{H}_{2} \mathrm{O}$ & 90 \\
$\mathrm{CoCl}_{2} \cdot 6 \mathrm{H}_{2} \mathrm{O}$ & 50 \\
$\mathrm{H}_{3} \mathrm{BO}_{3}$ & 50 \\
$\left(\mathrm{NH}_{4}\right)_{6} \mathrm{Mo}_{7} \mathrm{O}_{24}$ & 50 \\
$\mathrm{AlCl}_{3}$ & 50 \\
$\mathrm{Na}_{2} \mathrm{SeO}_{3} \cdot 5 \mathrm{H}_{2} \mathrm{O}$ & 50 \\
$\mathrm{EDTA}$ & 100 \\
\hline
\end{tabular}

(0.8 1) to avoid sludge sedimentation and "dead zones" at the reactor bottom. Feed was pumped intermittently into this phase using a peristaltic pump. The 0.151 biofilm phase contained a porous rock material (Light Expanded Clay Aggregates, "Leca" from Weber, Saint-Gobain) as the biofilm substratum contained within a plastic net. The upper suspended phase $(0.3 \mathrm{l})$ was intended as a second sludge bed reaction zone and sedimentation zone to retain sludge in the reactor. The reactor design was intended to achieve long solid retention times compared to hydraulic retention time to enable efficient cultivation of MEAw consuming biomass and allow relatively high OLR. A recycle rate of $25 \mathrm{ml} / \mathrm{min}$ was maintained by a peristaltic pump to fluidize the sludge.

\section{Experimental management}

The experiment was performed at $22 \pm 2{ }^{\circ} \mathrm{C}$. A preadaptation period of three months was applied first to adapt the inoculum to the feed substrate with MEAw. Then, 486 days of experimental data were collected and analyzed. The total feed COD concentrations applied varied in a range of 10-25 g/l, of which MEAw was 1.7-15 g COD/l. The co-substrate had a constant concentration of $\sim 9.6 \mathrm{~g} \mathrm{COD} / 1$ (Table 1).

In the pre-adaptation, MEAw concentration in the feed and OLR were kept low and increased carefully (upto $\sim 4 \mathrm{~g} \mathrm{MEAw/l)} \mathrm{to} \mathrm{avoid} \mathrm{biomass} \mathrm{loss} \mathrm{due} \mathrm{to}$ toxic and inhibitory effects. This adaptation period ended when continuous and relatively stable biogas generation was observed. After pre-adaptation, the experimental test was continuously operated with three distinct phases of different feeding strategies (Fig. 2). In phase 1 (0-181 days), MEAwr in feed COD was increased from 0.18 to a maximum of 0.62 , the corresponding OLR applied was from 0.25 to $2.82 \mathrm{~kg} \mathrm{COD} / \mathrm{m}^{3}$ day. This period was designed to get an overview of the digestibility of MEAw substrate and system capacity and data analysis on this period is published by Wang et al. (2013). Process stability was investigated in phase 2, where MEAwr was kept at around 0.5 (182-281 days) and the OLR was in the range of $2-2.62 \mathrm{~kg} \mathrm{COD} / \mathrm{m}^{3}$ day. High loads were tested in phase 3 (282-486 days), where MEAwr was elevated from 0.4 to 0.6 and OLR from 2.66 to a maximum of $5.03 \mathrm{~kg} \mathrm{COD} / \mathrm{m}^{3}$ day. OLR was reduced to $2.86 \mathrm{~kg} \mathrm{COD} / \mathrm{m}^{3}$ day while maintaining MEAwr at 0.6 at the end of phase 3. The feed COD variations were imposed by changing MEAw concentrations while the co-substrate COD concentrations remained constant (Table 1). The applied loads were varied by modifying either the MEAwr or increasing the feed loading (flow) rate.

The generated biogas was collected continuously in a gas bag (Cali-5-Bond) during the experiment (Fig. 1). The biogas volume and its composition were measured every 2 days. Liquid samples were collected from sample point 3 every 2 days (Fig. 1) for the measurements of $\mathrm{pH}, \mathrm{VFA}$, ammonia and soluble COD (sCOD) concentrations. The $\mathrm{pH}$ was analyzed 
Fig. 1 Schematic of the used anaerobic hybrid reactor system (Wang et al. 2013)

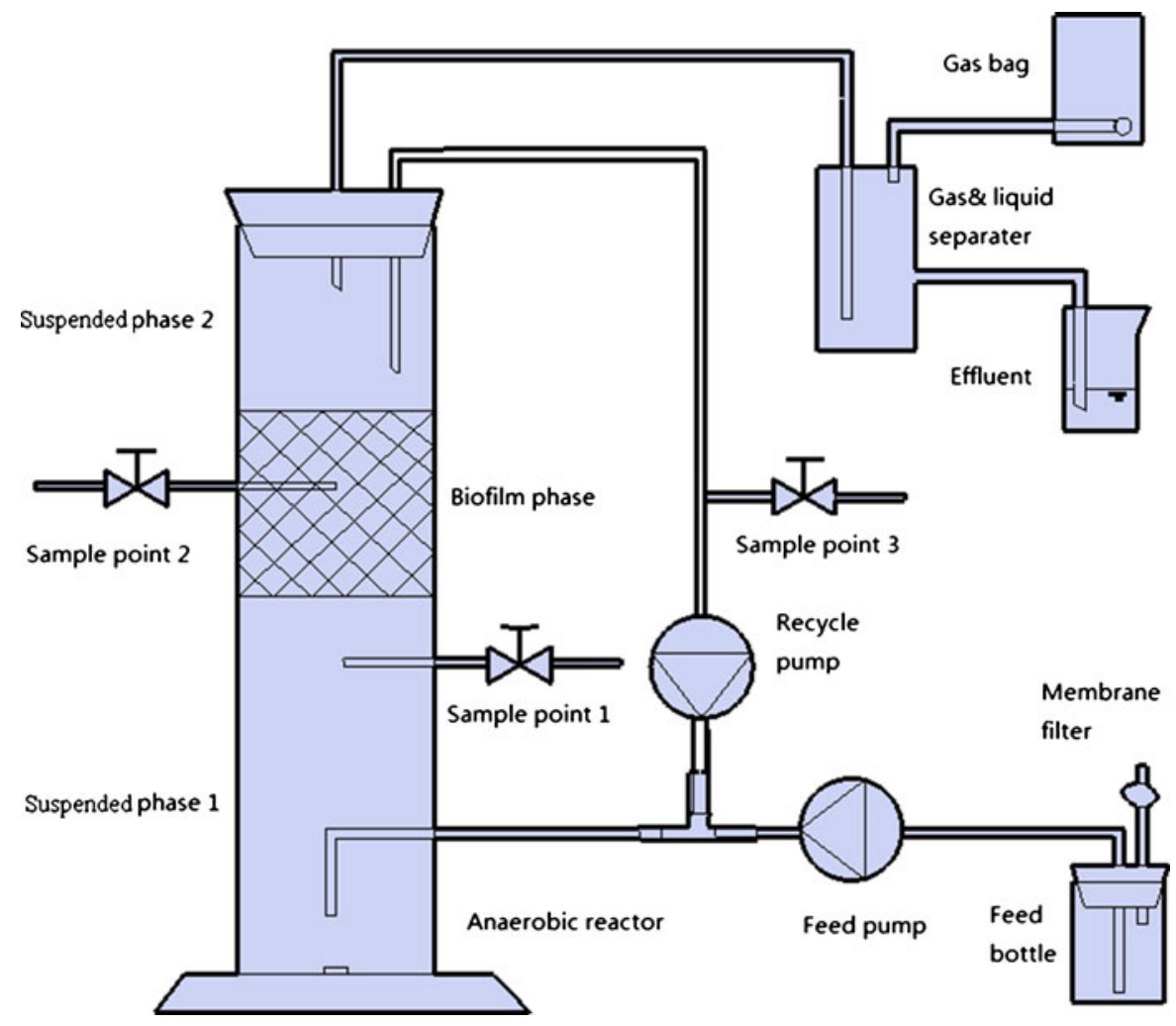

for each sample, while the analysis of VFA, ammonia and COD were conducted for every other sample due to the relatively small amount of samples collected.

Analytical methods

The analytical methods used for the measurements of VFAs, biogas composition, COD, MEA and ammonia concentrations and the calculation of total and free ammonia nitrogen concentration can be referred to Wang et al. (2013).

Principal component analysis, PCA, is a statistical technique to identify patterns in data, and express the data in a way to highlight similarities and differences (Abdi and Williams 2010). Correlation circle generated from PCA analysis was used to interpret the
Fig. 2 Feed and MEA waste COD concentration and organic loading rate (OLR) applied in the experiment test

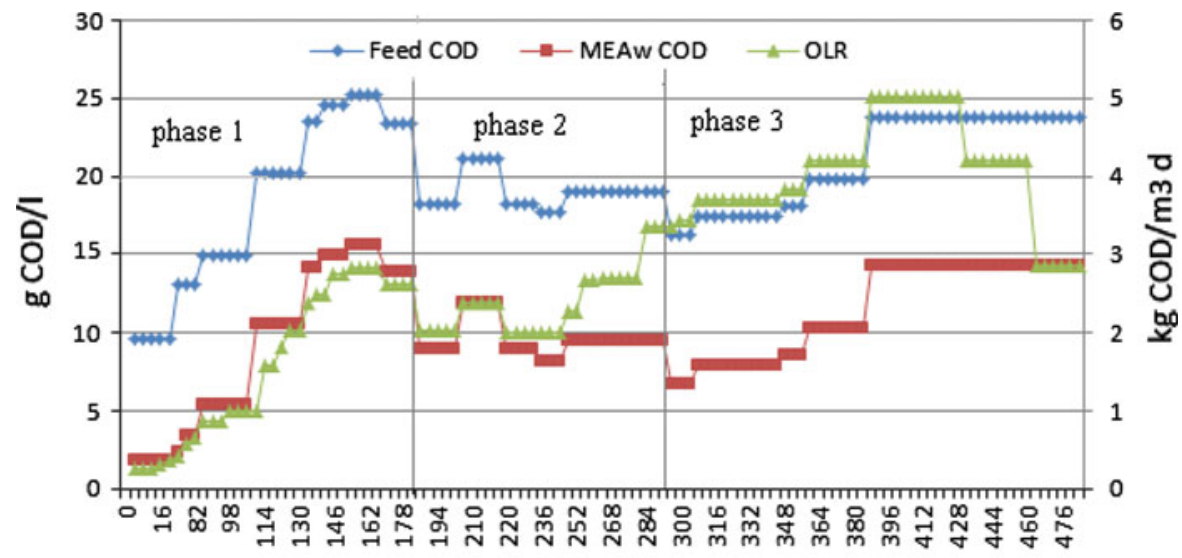

Day 
correlation between different variables used. Commercial Excel add-in software XLSTAT was used for the PCA analysis.

\section{Results and discussion}

The 486 days of anaerobic digester performance data were recorded and analyzed by assessing the COD and MEA waste removal efficiency and methane yield, showing that the extent of methane generation from waste degradation varied significantly. The influences of operational conditions and inhibition factors on anaerobic MEAw degradation are examined. Data from the first part of this experiment, published elsewhere (Wang et al. (2013)), are repeated here to more clearly show the digestion efficiency development during a long time span and compare results from a wide range of load conditions tested.

\section{COD removal}

The COD removal efficiency based on the influent and effluent soluble COD concentration measurements are given in Fig. 3. The COD removal efficiency was generally above $90 \%$ before day 108. Afterwards, it gradually decreased to $45 \%$ when the applied MEAwr increased above 0.5 to a maximum of 0.6 with OLR in the range from 1.5 to $2.8 \mathrm{~kg} \quad \mathrm{COD} / \mathrm{m}^{3}$ day (109-181 days). In light of the apparent impending system failure, MEAwr was reduced to around 0.5 while the OLR was maintained between 2 and $3 \mathrm{~kg}$ $\mathrm{COD} / \mathrm{m}^{3}$ day in phase 2 (182-282 days). During this period, COD removal efficiency recovered to about $80 \%$ in one month and then remained relatively constant at MEAwr of 0.5 and an OLR of about $2.5 \mathrm{~kg}$ $\mathrm{COD} / \mathrm{m}^{3}$ day.

In phase 3, the COD removal efficiency reached up to $90 \%$ again from 283 to 292 days, at a MEAwr of 0.5 and OLR of $3.43 \mathrm{~kg} \mathrm{COD} / \mathrm{m}^{3}$ day. The relatively high efficiency at a much higher OLR than that applied in phase 1 indicated that high OLR in the later part of phase $1\left(2.82 \mathrm{~kg} \mathrm{COD} / \mathrm{m}^{3}\right.$ day) was not the reason of the decreased removal efficiency. A stepwise increase of OLR to $5.03 \mathrm{~kg} \mathrm{COD} / \mathrm{m}^{3}$ day by increasing feed MEAwr from 0.4 to 0.6 decreased the removal efficiency again to about $65 \%$ (293-428 days). This decline reveals that the increase of MEAwr does negatively affect the removal efficiency. High MEAwr is evidently more challenging for the involved organisms than high MEAw loading rate. The system has high capacity in terms of organic loading.

A comparison of removal efficiency at a similar feed MEAwr to that applied in phase 1 around 160 days and after 400 days shows that the removal efficiency was higher in the latter case even at higher loading rates. It indicates that the organisms continued to adapt to the complex feed substrate and inhibitory factors that this feed may have presented or inhibitory products of MEAw degradation (e.g. $\mathrm{NH}_{3}$ ) through the whole test.

\section{Mass balance}

Mass balance for the main COD constituents, calculated at each sampling time based on the measured average methane generation, effluent VFA and effluent sCOD concentrations are shown in Fig. 4. Data, normalized to total feed COD, shows that $80-90 \%$ of the feed COD was recovered as methane and sCOD. A varying fraction of the SCOD was VFA, reaching a maximum of $\sim 50 \%$ during the highest load in phase 3 . The COD not accounted for in Fig. 4 (when total effluent/feed $\mathrm{COD}<1$ ) can be produced biomass accumulating in the reactor and/or leaving as particulate COD. Observed sedimentation of some feed starch on the wall of the feeding pipe may have contributed to loss of feed COD and mass balance errors. Glucose was used instead of starch after 250 days in the feed solution to avoid this potential error. Afterwards, methane COD and effluent sCOD added up to approx. 0.9 times feed COD, showing that $10 \%$ of the feed COD was converted to biomass and some was probably lost as recalcitrant chemicals absorbed to particles/biomass.

Figure 5 shows the combined methane and VFA COD to feed COD ratio with respect to applied MEAwr in feed to show how much of the feed was hydrolyzed and acidified (termed degradation ratio). Data from phase 1 shows that the degradation ratio decreased by a linear trend from about $0.8-0.5$ at the maximum MEAwr applied. Only about $50 \%$ of the feed COD was broken down at the highest MEAwr. The degradation ratio increased during the long adaptation period in phase 2 while maintaining relatively high MEAwr. After that the degradation efficiency during phase 3 was consistently higher than in phase 1 in the MEAwr range (0.4-0.6) tested. This clearly demonstrates the biomass adaptation to feed 
Fig. 3 COD removal efficiency $(\%)$ under different feed OLR and MEA waste ratios in feed

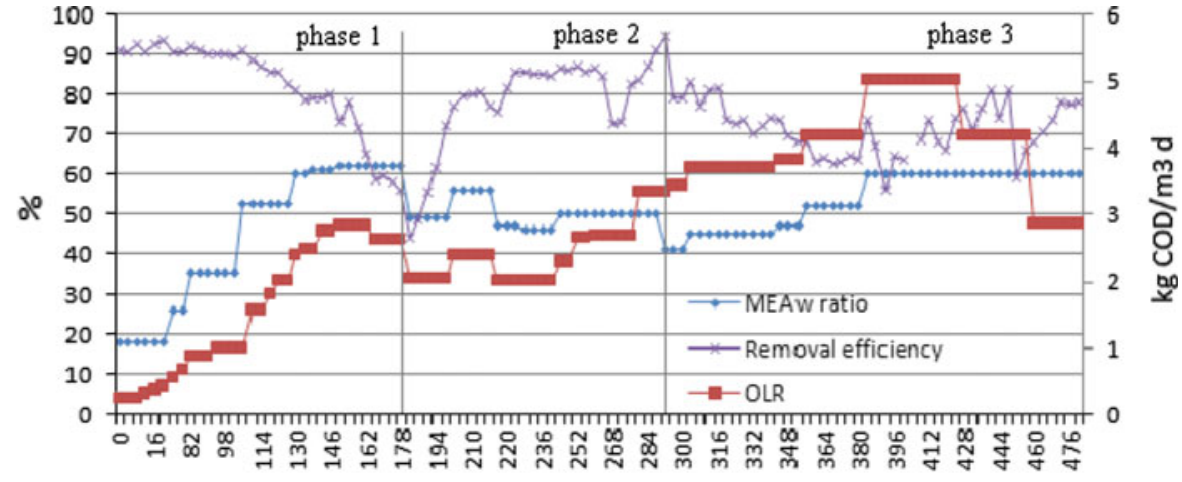

Day

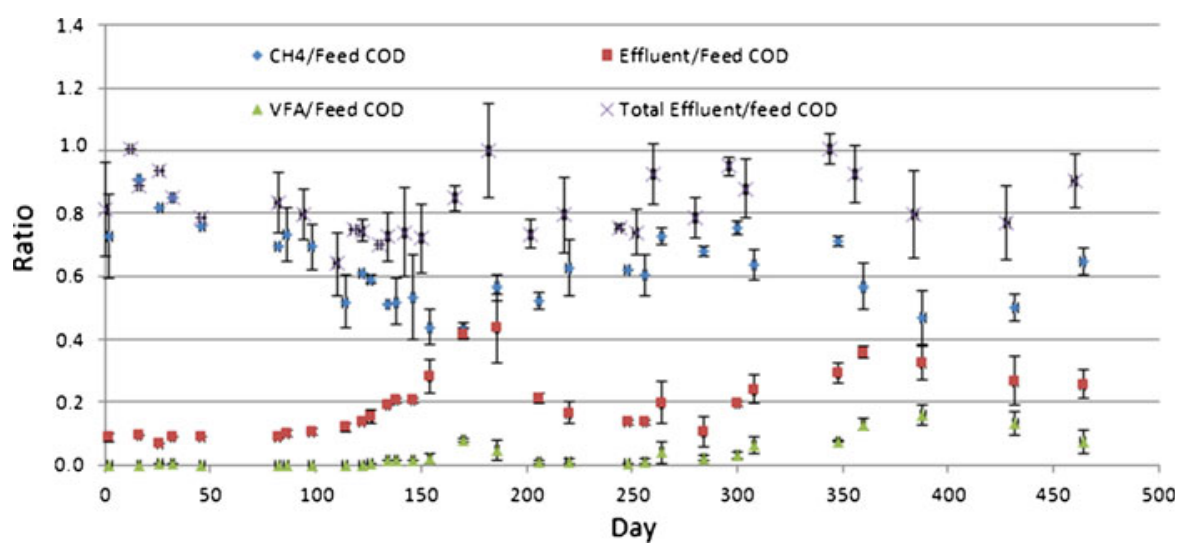

Fig. 4 Ratios of methane, VFA and effluent soluble COD to the total feed COD. Error bars represent one standard deviation

MEAw discussed above. The fraction of undetected substances in the feed that were reduced and degraded to methane and VFA still increased after hundreds of days of reactor operation.

$\mathrm{pH}$ and ammonia

The MEAw used had high alkalinity $\left(16 \mathrm{~g} \mathrm{CaCO}_{3} / 1\right.$ equivalent, for a $50 \mathrm{~g}$ MEAw/l solution in distilled water). The feed solution $\mathrm{pH}$ varied depending on the MEAw concentration and reached 10.5 when $25 \mathrm{~g}$ MEAw/l was applied. The digester effluent $\mathrm{pH}$ was measured in the range of 7.0-8.0 in the whole test period without applying $\mathrm{pH}$ adjustment in the AD. Even at the highest VFA accumulation (402-420 days, Fig. 7) the $\mathrm{pH}$ was well above 7 , attributed to the high alkalinity buffer capacity of the feed solution as well as the accumulated ammonia concentration (Fig. 6). The effluent VFA concentrations varied from 0 to a maximum of $4 \mathrm{~g} / \mathrm{l}$ and total and free ammonia nitrogen (TAN and FAN) reached maximums of $2.2 \mathrm{~g} / \mathrm{l}$ and $90 \mathrm{mg} / \mathrm{l}$, respectively (Figs. 6, 7).

Figure 6 shows the ammonia concentration variations in the digester for the whole test period. The TAN concentration reached a maximum of about $2.2 \mathrm{~g}$ $\mathrm{N} / \mathrm{l}$ at around 181 days and the highest FAN was $50 \mathrm{mg} \mathrm{N} / \mathrm{l}$ in phase 1. TAN and FAN concentrations decreased simultaneously as OLR and MEAwr reduced and then stayed relatively constant in phase 2. Ammonia concentration increased again when feed MEAwr increased in phase 3. TAN and FAN varied more in phase 3 and were $2.2 \mathrm{~g} \mathrm{~N} / \mathrm{l}$ and $90 \mathrm{mg} \mathrm{N} / \mathrm{l}$, respectively, at the end of the test.

\section{Inhibition}

Acetate was more than $90 \%$ of the VFA accumulated in the digester with minor accumulations of several 
Fig. 5 Combined VFA and methane COD to the feed COD ratio under different applied MEA waste COD ratios (MEAwr) in feed in the tested three phases; Error bars represent one standard deviation

Fig. 6 Reactor effluent $\mathrm{pH}$ and total and free ammonia nitrogen (TAN and FAN) concentrations under varying feed organic loading rate (OLR) during the test period
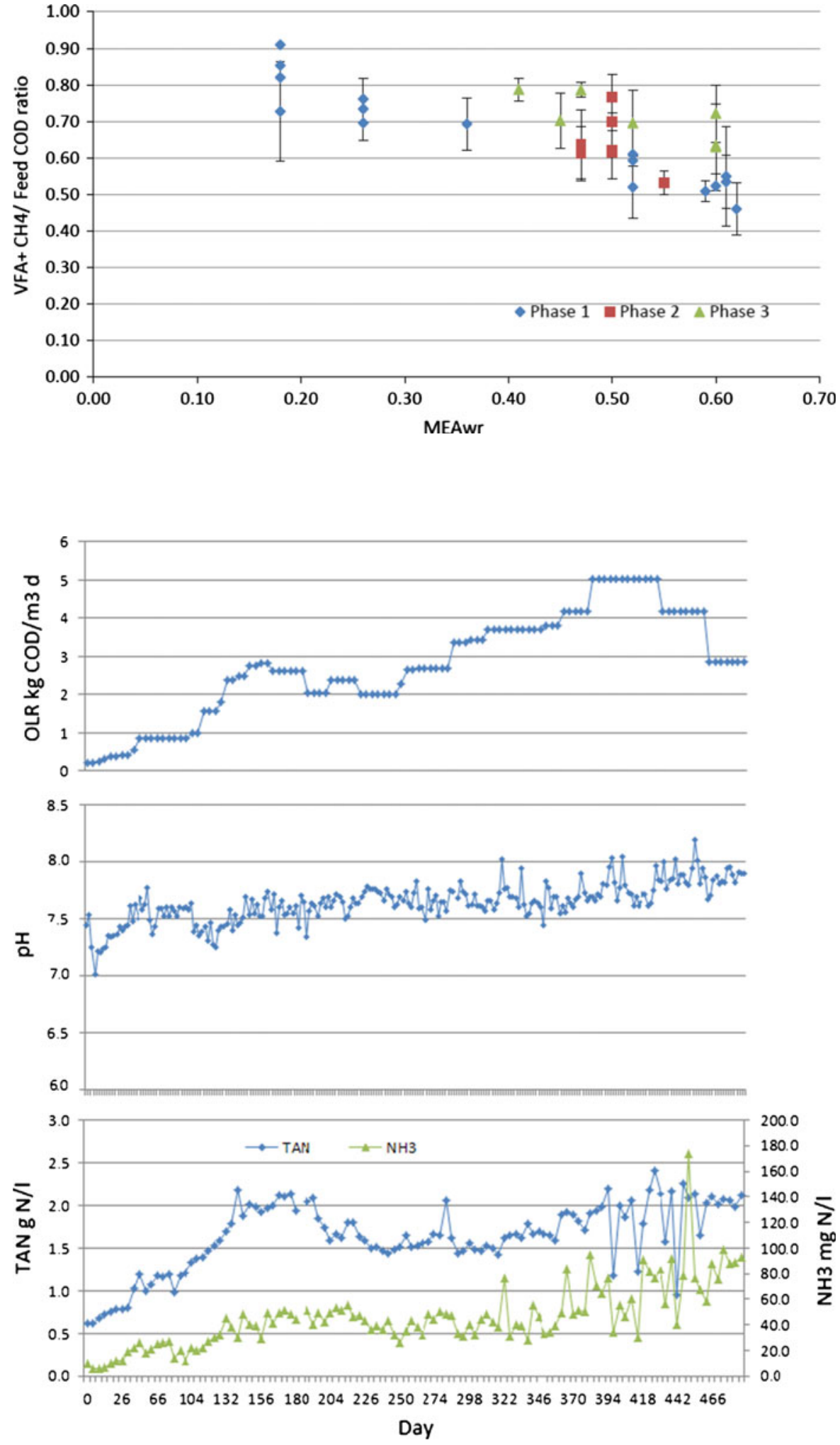
Fig. 7 Volatile fatty acid (VFA) accumulations under varying feed organic loading rate (OLR)
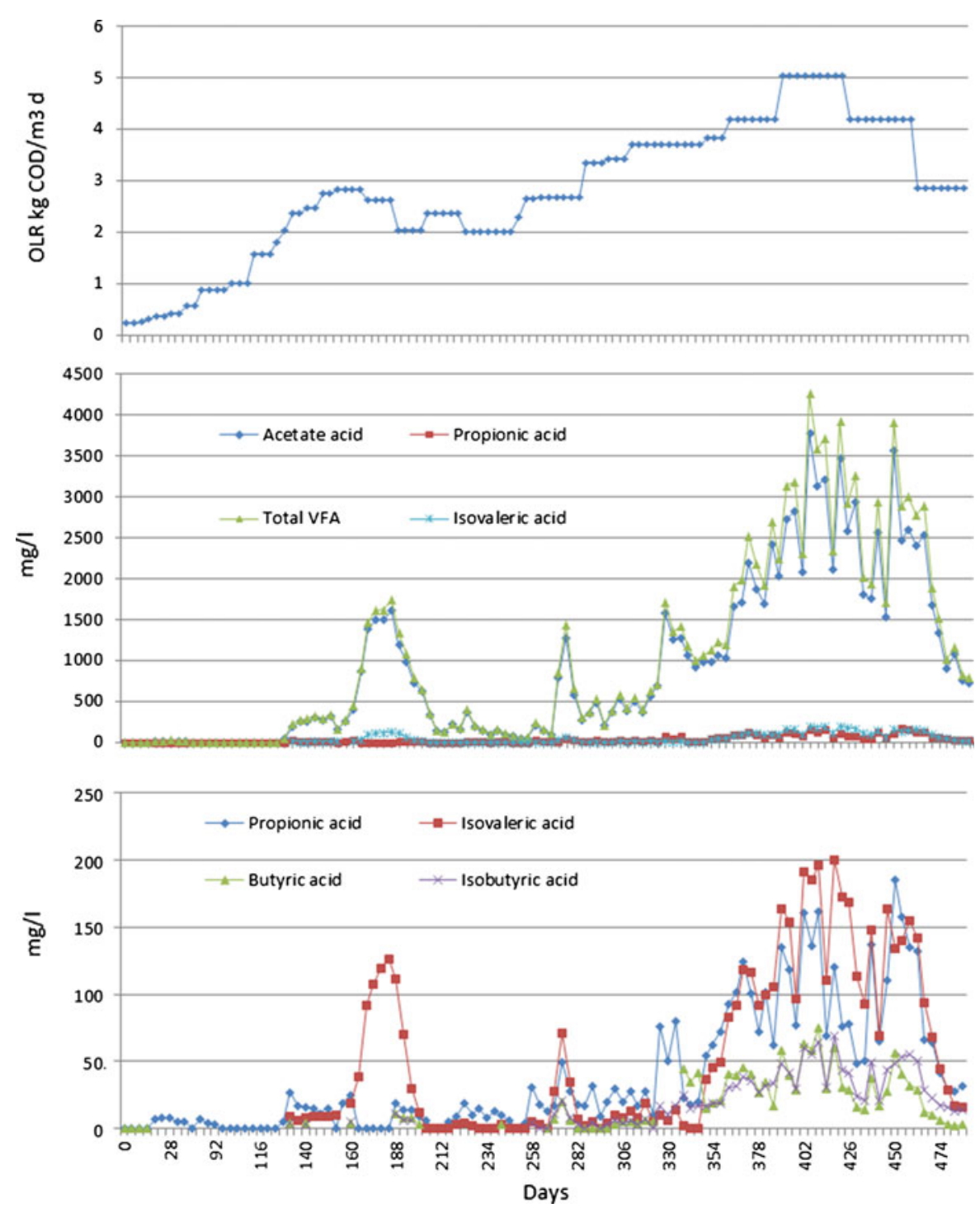

other fatty acids. Isovaleric, propionic, butyric and isobutyric acid were detected when acetate concentrations were high (Fig. 7).

VFA accumulated when the methane yield decreased, implying that inhibition of VFA consuming organisms is a reasonable explanation of the diminished methane yield during periods of high MEAwr. Acetoclastic methanogenesis is evidently especially sensitive to the factors causing the inhibition since most of the accumulated VFA was acetate (Fig. 7). High concentrations of free ammonia can also cause such inhibitions, but the levels observed here were low compared to those reported to cause inhibition (e.g. observed inhibition coefficient $\mathrm{K}_{\mathrm{i}}(50 \%)$ is $30-90 \mathrm{mg}$
N/l) (Gallert et al. 1998; Batstone et al. 2002). High tolerance of $800 \mathrm{mg} \mathrm{N} / \mathrm{l}$ was observed (Calli et al. 2005). It therefore, seems likely that some other constituents of MEAw and/or degradation products thereof contribute significantly to the observed inhibition. Complex and recalcitrant chemicals from MEAw may inhibit the anaerobic degradation and cause VFA accumulation. Anaerobic microbial consortia can adapt to high ammonia by establishing an alternative pathway (Schnürer et al. 1994). The observation of less VFA accumulation at similar feed MEAwr and OLR (0.6 and $2.82 \mathrm{~kg} \mathrm{COD} / \mathrm{m}^{3}$ day) at the end of phase 3 compared to phase 1 (Fig. 7) suggests that such an adaptation may have occurred. 


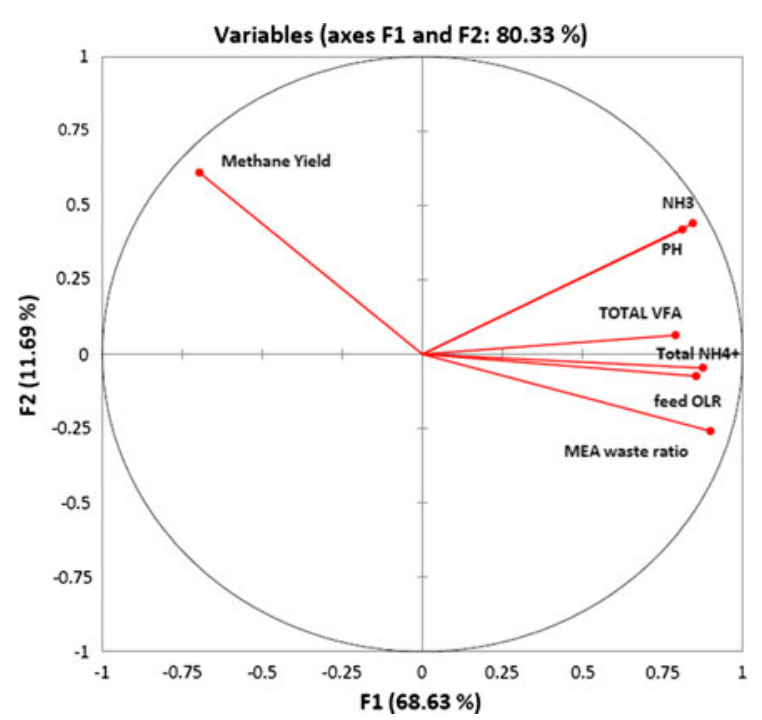

Fig. 8 Correlation circle (below on axes F1 and F2) shows a projection of the initial variables in the factors space, indicating the correlations between different variables. When two variables are far from the origin, if they are close to each other, they are significantly positively correlated; when they are opposite from each other, they are negatively correlated; when they are orthogonal to each other, they are not significantly correlated

This is supported by the observation that TAN was at a similar level in those two feed conditions while FAN concentrations were at a higher $(90 \mathrm{mg} / \mathrm{l}$ comparing to $50 \mathrm{mg} / \mathrm{l}$ ) level due to higher $\mathrm{pH}$ in phase 3 (Fig. 6). If FAN was the main inhibitory factor in phase 1 , it indicates that the biomass consortium gradually acclimated to the inhibitory ammonia, possibly by establishing the alternative pathway described by Schnürer et al. (1994).

Figure 8 shows the correlation circle from PCA, where a projection of the initial variables (methane yield, $\mathrm{pH}, \mathrm{NH}_{3}$, total VFA, feed OLR, total $\mathrm{NH}_{4}{ }^{+}$and MEAwr) are shown in the factors space. The correlation between variables can be interpreted through the angles of variable projections. When two variables are far from the origin and they are close to each other, such as $\mathrm{pH}$ and $\mathrm{NH}_{3}$, they are significantly positively correlated ( $\mathrm{r}$ close to 1). Methane yield is almost orthogonal to $\mathrm{pH}$ and $\mathrm{NH}_{3}$, implying that they are not significantly correlated ( $\mathrm{r}$ close to 0 ). MEAwr is on the opposite side of the center from methane yield, implying that they are significantly negatively correlated ( $\mathrm{r}$ close to -1 ). OLR and total ammonia which varied with the MEAwr applied are also quite on the opposite side of Methane yield, implying that these two variables may also strongly affect the methane yield. Total ammonia concentration and accumulated VFA may also cause stress in the methanogenic pathways and contribute to variations of the methane yield (Lü et al. 2013).

MEAwr played an important role in providing feed nitrogenous organics and thereby contributed to the ammonia accumulation when MEAw was degraded. PCA shows that MEAwr in feed is the most important impact negative factor to the methane yield, more so than FAN and TAN (Fig. 8). This supports the claim that some other constituents of MEAw and/or degradation products from such are the cause of, or contribute significantly, to the observed inhibition.

\section{Conclusion}

Anaerobic degradation of MEAw with easily degradable co-digestible substrates was conducted in a hybrid anaerobic digester for 486 days at room temperature. The mixed feed substrate degradation ratio reached a maximum of $93 \%$ when no inhibition effects were observed at low MEAwr $(<0.5)$ and OLR $<3 \mathrm{~kg} \mathrm{COD} / \mathrm{m}^{3}$ day. Principal component analysis showed a strong negative correlation between MEAwr and methane yield in the load range tested, MEAwr $>0.5$ reduced methane yield. VFA, mainly as acetate, accumulated with high MEAwr causing inhibitory conditions implying that acetoclastic methanogenesis was the step that was mainly inhibited. Complex and recalcitrant chemicals in MEAw and products of degradation, including ammonia, may be the cause of the inhibited AD performance. Significantly less inhibition was observed after a year of operation compared to the first phase of the experiment implying some microbial adaptation to the inhibiting factors. High MEA waste removal efficiency by AD can thus be achieved by cultures adapted to such feed in an appropriate co-substrate mixture. Relatively stable system performance can be obtained given moderate load changes.

Acknowledgments The Research Council of Norway (Climit Programme) and the industry partners, Hydro Aluminium AS, Noretyl AS, Norcem AS, NOAH AS, E.On Sverige AB, Elkem Thamshavn AS, Aker Clean Carbon AS are acknowledged for their support. 
Open Access This article is distributed under the terms of the Creative Commons Attribution License which permits any use, distribution, and reproduction in any medium, provided the original author(s) and the source are credited.

\section{References}

Abdi H, Williams LJ (2010) Principal component analysis. John Wiley \& Sons. WIREs Comp Stat 2:433-459

Barchas R, Davis R (1992) The Kerr-McGee/ABB lummus crest technology for the recovery of $\mathrm{CO}_{2}$ from stack gases. Energy Convers Manag 33(5-8):333-340

Batstone DJ, Keller J, Angelidaki I, Kalyuzhnyi S, Pavlostathis SG, Rozzi A, Sanders W, Siegrist H, Vavilin V (2002) Anaerobic digestion model No 1 (ADM1). Sci Technol 45:65-73

Botheju D, Li Y, Hovland J, Haugen HA, Bakke R (2011) Biological treatment of amine wastes generated in post combustion $\mathrm{CO}_{2}$ capture. Energy Proc 4:496-503

Calli B, Mertoglua B, Inancb B, Yenigunc O (2005) Effects of high free ammonia concentrations on the performances of anaerobic bioreactors. Proc Biochem 40:1285-1292

Chen Y, Cheng JJ, Creamer KS (2008) Inhibition of anaerobic digestion process: a review. Bioresour Technol 99:4044-4064

Davis J, Rochelle GT (2009) Thermal degradation of monoethanolamine at stripper conditions. Energy Proc 1:327-333

Gallert C, Bauer S, Winter J (1998) Effect of ammonia on the anaerobic degradation of protein by a mesophilic and thermophilic biowaste population. Appl Microbiol Biotechnol 50:495-501

Goff G, Rochelle G (2004) Monoethanolamine degradation: $\mathrm{O}_{2}$ mass transfer effects under $\mathrm{CO}_{2}$ capture conditions. Ind Eng Chem Res 43:6400-6408

Hansen KH, Angelidaki I, Ahring BK (1998) Anaerobic digestion of swine manure: inhibition by ammonia. Water Res 32(1):5-12

Hauser I, Skjæran JA, Einbu A, Østgaard K, Svendsen HF, Cervantes FJ (2013) Biodegradation of amine waste generated from post-combustion $\mathrm{CO}_{2}$ capture in a moving bed biofilm treatment system. Biotechnol Lett 35:219-224

IEA (2012) Emissions of substances other than $\mathrm{CO}_{2}$ from power plants with CCS. IEA Report Publication number: IEA GHG 2012-03

Lü F, Hao L, Guan D, Qi Y, Shao L, He P (2013) Synergetic stress of acids and ammonium on the shift in the methanogenic pathways during thermophilic anaerobic digestion of organics. Water Res 47:2297-2306

Schnürer A, Zellner G, Svensson BH (1994) Mesophilic syntrophic acetate oxidation during methane formation in biogas reactor. Arch Microbiol 162:70-74

Strazisar BR, Anderson RR, White CM (2003) Degradation path ways for monoethanolamine in a $\mathrm{CO}_{2}$ capture facility. Energy Fuel 17:1034-1039

Thitakamol B, Veawab A, Aroonwilas A (2007) Environmental impacts of absorption-based $\mathrm{CO}_{2}$ capture unit for postcombustion treatment of flue gas from coal-fired power plant. Int J Greenh Gas Control 1:318

Wang S, Hovland J, Bakke R (2013) Anaerobic degradation of carbon capture reclaimer MEA waste. Water Sci Technol 67:2549-2559 